\title{
A propósito de la dirección de tesis doctorales de Biblioteconomía y Documentación en las universidades españolas (1982-2020)
}

\author{
Regarding the direction of doctoral theses in Library \\ and Information Science in Spanish \\ universities (1982-2020)
}

\author{
José López-Yepes
}

Cómo citar este artículo:

López-Yepes, José (2020). “A propósito de la dirección de tesis doctorales de Biblioteconomía y Documentación en las universidades españolas (1982-2020)". Profesional de la información, v. 29, n. 5, e290511.

https://doi.org/10.3145/epi.2020.sep.11

Carta recibida el 15-09-2020

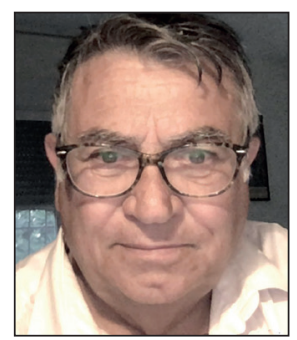

\author{
José López-Yepes \\ https://orcid.org/0000-0002-7068-6154 \\ Catedrático emérito \\ Universidad Complutense de Madrid \\ Madrid, España \\ Tel.: +34-689060178 \\ yepes@ucm.es
}

\section{Sr. Director de Profesional de la información}

En las líneas que siguen propongo algunas ideas sugeridas por la lectura del magnífico artículo redactado por los doctores Gregorio González-Alcaide y Aurora González-Teruel ${ }^{1}$. Y digo magnífico porque han encarado con acierto un tema de gran trascendencia sobre autores y directores de tesis doctorales en el área de Biblioteconomía y Documentación y han aportado ideas muy interesantes y dignas de nuevos estudios. Lo que deseo aportar tan solo son contenidos complementarios a cuestiones sobre las que he tenido ocasión de reflexionar a lo largo de mi vida académica y basadas en la experiencia (nunca determinante y perfecta como todas las experiencias) de haber sido el primer catedrático de universidad de nuestra área (por orden cronológico), haber impulsado centros, departamentos y titulaciones, haber fundado y dirigido tres revistas científicas, haber participado como evaluador de la Aneca en el programa Academia de acreditación durante varios años y haber publicado algunos trabajos sobre problemas generales de las tesis y dirigido cincuenta y siete tesis doctorales desde 1982 hasta el presente año 2020. Podría, incluso, añadir que he tenido y tengo una enorme atracción hacia las cuestiones de metodología de la investigación y de asesoramiento de tesis doctorales además del ejercicio práctico en la dirección de las mismas y en la promoción y formación de investigadores en diversas universidades.

Ciertamente, y de ello me congratulo, la bibliografía sobre los temas de referencia ha sido relativamente abundante y de ello una buena muestra se utiliza en el artículo de referencia. Mis reflexiones requieren, para mejor justificarlas, plantear de entrada tres circunstancias:

1) Nuestro ámbito del saber se incorporó oficialmente muy tarde a la universidad española. Sin perjuicio de la existencia de la cátedra de Bibliografía en la Facultad de Filosofía y Letras de la Universidad Complutense de Madrid ejercida por el Dr. José Simón Díaz, uno de mis maestros, en 1978 se proveyó la primera plaza de Profesor Agregado de Documentación, precisamente en la Facultad de Ciencias de la Información en la citada universidad y, en 1980, la primera cátedra 
el mismo centro. A lo largo de esa década ya entraron en funcionamiento las Escuelas Universitarias de Biblioteconomía y Documentación y, cuando se estableció la titulación de Licenciado (en algunas universidades los estudios de Biblioteconomía y Documentación se adscribieron a Facultades desde un principio) y la conversión de las Escuelas en Facultades, se inició la elaboración de tesis doctorales. Procede pues, sostener que en 1982 se presentó la primera tesis doctoral propia de centros donde se impartía específicamente Documentación, en la Universidad Complutense de Madrid y, en 1983 en la Universidad Autónoma de Barcelona ${ }^{2}$.

2) Los datos estadísticos que ofrecen las bases de datos cuantitativas procedentes de revistas agrupadas en Scopus y $\mathrm{SSCl}$ deben también completarse con las agrupadas en Emerging Sources Citation Index y otras. Y, en todo caso, deben completarse con otras fuentes y siempre exhibiendo un exquisito cuidado en tratar de no convertir los datos estadísticos en observaciones cualitativas a falta de otros apoyos.

3) La realización de una tesis doctoral, como en otras tareas universitarias, no es tarea "químicamente pura". La investigación científica es ciencia y pasión. La tesis doctoral es conocimiento y sentimientos ${ }^{3}$. La relación director/dirigido despierta afecto y compañerismo. Ambos son responsables del buen fin del trabajo. Las alegrías y las decepciones se entremezclan en el proceso de modo similar al estado de ánimo que se experimenta al alcanzar la cima de una montaña que se persigue con obsesión ${ }^{4}$.

Nuestros colegas Gregorio González-Alcaide y Aurora González-Teruel plantean muy oportunamente y con una metodología correcta, a mi entender, notables aspectos vinculados a la dirección de tesis, a saber,

- su volumen y el porcentaje de participación del profesorado en esta labor;

- el grado de concentración en las direcciones y la presencia de las codirecciones, y

- la posible coincidencia de las líneas de investigación de las tesis con las áreas temáticas de los directores.

Hay, en mi opinión, otras cuestiones que forman parte de la problemática que nos ocupa y que también deberían debatirse en otro momento como son las acciones encaminadas a la formación de investigadores ${ }^{5}$ y directores ${ }^{6}$, al establecimiento de criterios objetivos para la evaluación de las tesis ${ }^{7}$, y a cuestiones relacionadas con la ética en el proceso de su elaboración ${ }^{8}$.

Como se sabe, los trabajos de fin de grado, de máster y de tesis doctoral son los instrumentos, además de la enseñanza, de que dispone la comunidad científica para garantizar que los egresados se han convertido en intelectuales, es decir, en poseedores del oficio del pensamiento, o, lo que es lo mismo, en personas capaces de obtener nuevo conocimiento científico y de aplicar criterios propios en su quehacer intelectual. La tesis doctoral supone la culminación de la carrera del estudiante y requiere, entre otros elementos, un objeto de investigación suficientemente amplio y de notable trascendencia y un director que le enseñe a investigar.

En efecto, la formación del estudiante para lograr tal propósito se logra en la acción (se aprende a investigar investigando), por medios indirectos como asistencia a seminarios de investigación y lectura de manuales del tema pero, sobre todo, por la ayuda del llamado director de tesis. Esta figura es insustituible, es el guía que acompaña al novel investigador en el recorrido de la ruta y es conocido en las legislaciones universitarias, con ligeras variantes, por tres nombres: tutor (el que protege), asesor (el que aconseja) y director (el que guía). De hecho, la ayuda del director se extiende a lo largo de un amplio iter desde la elección de tema hasta la publicación y evaluación definitiva del trabajo por la comunidad científica ${ }^{9}$ y se trata no solo de una ayuda técnica corresponsable sino también de una ayuda afectiva y de apoyo moral. Más allá de la aprobación de la tesis, el director suele convertirse, con frecuencia, en amigo del doctorando y su orientador permanente.

El extenso elenco de funciones atribuibles a un director, elegible en muchas ocasiones por el doctorando, exige del primero una adecuada preparación para ello. De hecho, la "escuela de directores" se deduce de la formación que hayamos adquirido con el profesor que dirigió nuestra propia tesis. De aquí se infiere que cuando el proceso formador no ha sido correcto el nuevo doctor se convierte en director de nuevos investigadores con la trascendencia negativa que ello puede suponer, incluso para la reputación del departamento respectivo y de la propia universidad donde se ha desempeñado dicho proceso. En realidad, las condiciones que debe reunir un director para hacer bien su papel son tres:

- que la temática de la tesis se inscriba en el ámbito de su dedicación o especialización docente e investigadora;

- que tenga experiencia en la investigación como solucionador de problemas científicos y también, si es posible, experiencia como director de trabajos;

- finalmente, la tercera condición es que le guste dirigir o, dicho en otros términos, que sea consciente de que en este trabajo se enriquece aprendiendo conjuntamente con su dirigido y contribuye, por tanto, al crecimiento del saber que cultiva a pesar del tiempo y las preocupaciones que conlleva la dirección. 
Hemos comprobado que hay colegas que declinan la dirección de tesis y, por el contrario, jamás he constatado que a algunos jóvenes profesores se les niegue por razones personales o de jerarquía la posibilidad de la dirección. Por el contrario, con frecuencia la codirección se emplea como recurso para la iniciación de los profesores más jóvenes y últimamente como recurso para enriquecer el curriculum.
No me parece acertado relacionar de modo determinante la concentración de direcciones de tesis con la merma de calidad o como clara manifestación de abuso de jerarquía

De otra parte, no me parece acertado relacionar de modo determinante la concentración de direcciones de tesis con la merma de calidad o como clara manifestación de abuso de jerarquía. Nada nos impide pensar que los directores más productivos pueden serlo porque tienen mayor antigüedad en el empleo, tienen vocación por la dirección, han promovido la formación de investigadores y han dedicado con ilusión y entusiasmo propios de la tarea universitaria muchas horas de su tiempo a esta tarea. Pero, sin duda, este tema afecta personalmente al autor de estas líneas y a otros colegas de todos conocidos. En nuestro caso, las razones que podemos esgrimir son las siguientes:

1) Haber tenido el privilegio de promover un departamento de documentación a fines de la década de los 70 hacía necesario que los docentes del mismo obtuvieran el grado de doctor y lo mismo en la promoción de otros centros;

2) La productividad de tesis doctorales en universidades como la UCM y la Carlos III se deriva también y sencillamente del mayor número de alumnos acogidos en sus aulas,

3) La expansión del departamento de la UCM en Iberoamérica se tradujo en la implantación de un programa de doctorado que atrajo a 42 docentes o profesionales mexicanos a doctorarse en nuestro departamento, bajo la dirección prioritaria de miembros del mismo, a fin de consolidar sus centros de trabajo. Un ejemplo es el actual Instituto de Investigaciones Bibliotecológicas y de la Información (IIBI) de la UNAM ${ }^{10}$. Otras universidades como las de Granada y de Salamanca, entre otras, han llevado a cabo iguales tareas.

4) La llamada concentración de tesis doctorales dirigida por pocos docentes también ha servido para iniciar líneas de investigación y consolidarlas a través de los llamados focos de investigación y escuelas científicas ${ }^{11}$ lo cual no comporta necesariamente un cuestión de endogamia o un obstáculo para el desarrollo de la disciplina; tan solo significa que cada departamento o núcleo docente se especializa en una o varías líneas temáticas, lo que a su vez permite que el doctorando pueda acudir al foco académico donde hay más especialistas en la línea en que desea formarse.

Algunas críticas se han deslizado por los autores del artículo hacia los directores con mayor número y su eventual especialización en muchos casos, su visibilidad internacional o que sus tesis no hayan tenido repercusión internacional. Y son críticas bien encaminadas aunque creo difícilmente demostrables y por tanto materia de opinión que respeto. En nuestro caso, como no podía se de otra manera, hemos abordado siempre temas que podíamos manejar y, con frecuencia, con ayuda de otro director más competente en otros aspectos del tema. Por otra parte, hemos contribuido a la evaluación objetiva de la calidad de la tesis ofreciendo criterios mínimos de aplicación rápida ${ }^{12}$. También podría considerarse un indicador de calidad de las tesis su contribución a fijar el estatus docente o profesional de los investigadores a los que hemos tenido el honor de dirigir en universidades españolas y mexicanas ${ }^{13}$. Como muy bien indican nuestros compañeros Aurora González Alcaide y Gregorio González Teruel, se hace necesario un análisis más en profundidad

He observado un sesgo que en mi opinión contamina el proceso de elaboración de tesis doctorales basado en la urgencia y fiebre por la evaluación como instrumento de promoción profesional

"identificando las escuelas académicas y las genealogías derivadas de los procesos de dirección".

Concluyo compartiendo con mis compañeros autores algunas de las preocupaciones que muestran acerca de la dirección y elaboración de tesis doctorales en nuestro campo. A mayor abundamiento, he observado un sesgo que contamina en mi opinión el proceso basado en la urgencia y fiebre por la evaluación como instrumento de promoción profesional. Ello está conduciendo a que numerosos trabajos se hacen con vistas a ser evaluados primordialmente -con temas de moda y a veces incluso inanes- y no a resolver problemas de calado cuyas soluciones permitan resolver otros problemas importantes. Yo diría que estamos comenzando a sustituir la pasión por investigar y descubrir -el otium provechoso- por el nec-otium.

\section{Notas}

1. González-Alcaide, Gregorio; González-Teruel, Aurora (2020). “Dirección de tesis doctorales como reflejo de la Biblioteconomía y Documentación académica española: actores y temas". Profesional de la información, v. 29 , n. 4, e290441. https://doi.org/10.3145/epi.2020.jul.41

2. Caridad-Sebastián, Mercedes (1982). La teledocumentación y sus repercusiones en el desarrollo de la investigación científica. Dir.: José López-Yepes. 
Fuentes-Pujol, Eulàlia (1983). Diaris de Barcelona. Realitat i propostes per a un millor tractament documental. Dir.: Luis Núñez-Ladeveze.

3. López-Yepes, José (2020). La universidad como tejido de ideas y sentimientos (en prensa).

4. López-Yepes, José (2015). "Las tareas de apoyo del director en lo concerniente a los aspectos psicológicos, afectivos, éticos, creativos y de asunción de corresponsabilidad”. En: López-Yepes, José (2015). La dirección/asesoría de tesis. México DF, Universidad Panamericana, pp. 153-179.

5. López-Yepes, José (1995). La aventura de la investigación científica. Guía del investigador y del director de investigación. Madrid: Síntesis.

López-Yepes, José (2010). Cómo se hace una tesis doctoral. Trabajos de fin de grado, de máster y tesis doctorales. México DF: Library Outsourcing Services.

López-Yepes, José (2017). Aprender a investigar viendo cine. Madrid: Icadémica.

Desantes-Guanter, José-María; López-Yepes, José (1996). Teoría y técnica de la investigación científica. Madrid: Síntesis.

6. López-Yepes, José (2015). La dirección/asesoría de tesis. Materiales para un manual de buenas prácticas. México, DF: Universidad Panamericana.

7. López-Yepes, José (2005). “Las tesis doctorales en Biblioteconomía y Documentación. Diagnóstico y propuesta de criterios de evaluación". Documentación de las ciencias de la información, n. 28, pp. 173-187.

López-Yepes, José (2008). “Criterios para la evaluación de las tesis doctorales” (Grupo de investigación Otlet). Revista general de información y documentación, n. 18, pp. 293-322.

8. López-Yepes, José (2019). "A propósito de la ética en la investigación científica”. En: Torres-Vargas, A. y Fernández-Bajón, M. Teresa. Verdad y falsedad de la información. Ciudad de México: UNAM, IIBI, pp. 75-124.

9. López-Yepes, José (2015). La dirección/asesoría... op. cit.

10. López-Yepes, Alfonso (coord.) (2020). Las Ciencias de la Información y Documentación en la universidad española y su repercusión en Iberoamérica. La actividad docente e investigadora del Departamento de Biblioteconomía y Documentación de la Universidad Complutense de Madrid a través de su Servicio de Documentación Multimedia (1975-2020). Madrid: Dpto.Biblioteconomía y Documentación, UCM, 37 pp.

https://eprints.ucm.es/60038

11. López-Yepes, José (2002). “Focos de investigación y escuelas científicas en Documentación a través de la realización y dirección de tesis doctorales. El caso del Departamento de Biblioteconomía y Documentación de la Universidad Complutense de Madrid (1983-2001)". Documentación de las ciencias de la información, v. 5, pp. 19-54.

12. López-Yepes, José (2008). “Criterios para la evaluación...”, op. cit. en nota 7.

13. De las 57 tesis doctorales dirigidas por nosotros en el período 1982-2000 se desprenden los siguiente datos:

A) Universidades en que se han presentado: Universidad Complutense de Madrid: 50; Universidades de Murcia y Zaragoza: 2: Universidades de Alcalá, Politécnica de Madrid y Extremadura: 1.

B) Situación académica y laboral de una parte de los doctores: Catedráticos de Universidad: 6; Profesores Titulares de Universidad: 8; Directores de centros en la Universidad Nacional Autónoma de México y Universidad de San Luis Potosí: 7; Investigadores titulares en la UNAM y en la Universidad Panamericana de México: 13.

José López-Yepes es Catedrático emérito de la Universidad Complutense de Madrid y Doctor Honoris Causa por la Universidad Mayor de San Andrés, La Paz (Bolivia).

yepes@ucm.es 